\title{
An isolated capitellum fracture of the humerus in adult: $A$ rare case report
}

\author{
RP Shah Kalawar, P Chaudhary, R Maharjan, SF Afaque \\ Department of Orthopaedics \\ B.P. Koirala Institute of Health Sciences, Dharan, Nepal
}

\begin{abstract}
Introduction: Isolated capitellum fractures are rare and represent only $1 \%$ of all elbow fractures and $6 \%$ of distal humeral fractures. Case description: A 45-year-old right hand dominant female presented to us with pain and stiffness in her left elbow following a fall onto the outstretched hand that occurred 6 months prior. She had capitellum fracture with avascular changes and excision of the fractured fragment was done. Physiotherapy was initiated with outcome of nearly normal elbow function. At the time of injury, she was unable to move her elbow actively due to pain and she was misdiagnosed as soft tissue injury earlier in a local hospital. Conclusion: Possibility of rare diagnosis such as capitellum fracture should also be kept in mind while treating elbow injuries.
\end{abstract}

Key words: Avascular necrosis, capitellum fracture

\section{Introduction}

Isolated capitellum fractures are rare and represent only $1 \%$ of all elbow fractures and $6 \%$ of distal humeral fractures ${ }^{1-3}$. The mostly cartilaginous composition of the capitellum below 10 years age makes it more resistant to stress. Therefore, a fall on the outstretched hand (which is the mechanism of injury in most of these cases) is more likely to produce a supracondylar or lateral condylar fracture. As the capitellum grows and ossifies in older children, it becomes more susceptible to

\section{Address for correspondence}

Dr. Rosan Prasad Shah Kalawar

Department of Orthopaedics

B.P. Koirala Institute of Health Sciences, Dharan

Email:docrosan@yahoo.com shear injury ${ }^{4,5}$. A fracture of the capitellum is an osteochondral fracture and is entirely intra-articular. The epicondyle, the growth plate and the metaphysis are not involved, and the posterior part of the lateral condyle remains intact.

The presently accepted classification systems of capitellum fractures are descriptive and not treatment-directed $^{6}$. Bryan and Morrey classified capitellum fractures as Type 1, 2 and 3 [1]. Type 1, often referred to as the Hahn-Steinthal fracture, is a shear fracture in the coronal plane involving most of the capitellum and little or none of the trochlea. Type 2, called the Kocher-Lorenz fracture, 
and involves a variable amount of articular cartilage of the capitellum with minimal attached subchondral bone. Type 3 is a comminuted or compression fracture of the capitellum. McKee and colleagues described a fourth type, a shear fracture of the distal aspect of the humerus in the coronal plane including the capitellum and most of the trochlea (Figure 1) ${ }^{7}$. Ring and colleagues reported another descriptive classification for distal humeral articular fractures and, recently, Dubberley and colleagues proposed a novel classification system ${ }^{8}$. As a result of the rarity of capitellum fractures, studies focusing on this injury are insufficient ${ }^{4,9}$.

In adults, a variety of treatment methods have been described. As this type of fracture became better recognized in the adult population, treatment options evolved from closed reduction and immobilization, or excision of the capitellum, to open reduction and internal fixation in order to achieve a stable anatomic reduction ${ }^{2,3,6}$.
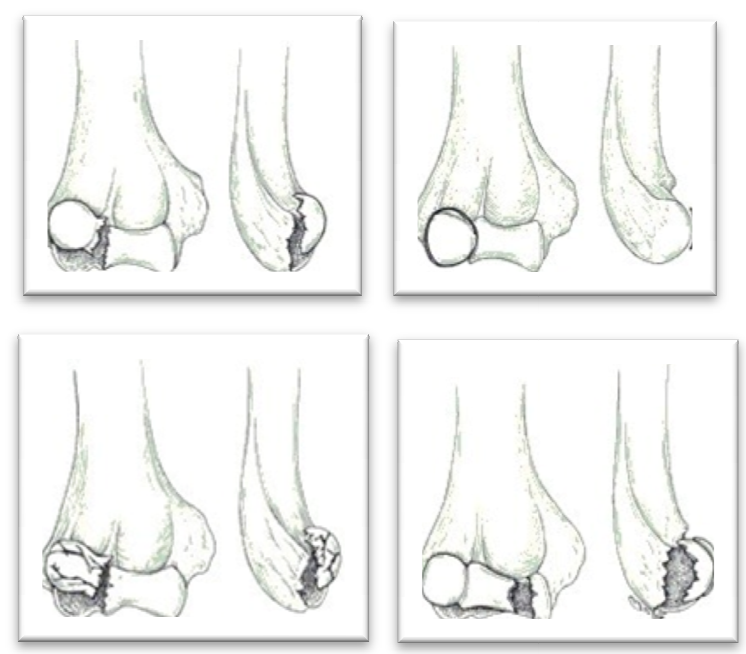

Fig. 1: Bryan and Morrey classification of Capitellum fracture

\section{Case description}

We describe the case of a 45 year old right hand dominant female who presented to us with pain and stiffness in her left elbow following a fall onto the outstretched hand that occurred 6 months prior. At the time of injury, she was unable to move her elbow actively due to pain and she was treated as soft tissue injury in a local hospital.

On presenting to our OPD after 6 months of injury, physical examination revealed stiff elbow fixed at 90 degree of flexion with jog of movements and tenderness over lateral aspect of distal part of her humerus. Joint stability was normal and no distal neurovascular deficits were noted. The diagnosis was made on a lateral and an AP radiograph and confirmed by $\mathrm{CT}$ elbow which revealed a displaced fracture of the capitellum. On radiograph a typical HahnSteinthal or Type I fracture was noted, margins appeared to be sclerotic, localized osteopenia was noted followed by variable density. Cortex collapse and fragments, with superimposed secondary degenerative change was also noticed which was suggestive avascular necrosis of capitellum (fig $2 \mathrm{a}$ and $2 \mathrm{~b}$ ). 


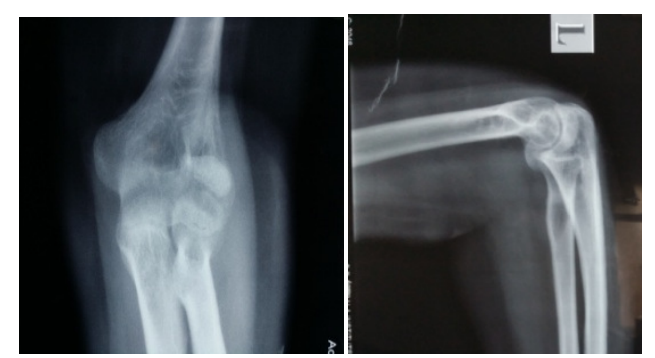

Fig. 2a and 2b: X-ray showing capitellum fracture with avascular necrosis

Patient was treated by excision of the capitellum through lateral approach and mobilization of elbow under anesthesia (Figure 3). Postoperatively, her elbow was placed in an arm sling at a right angle, with the forearm in a neutral position.
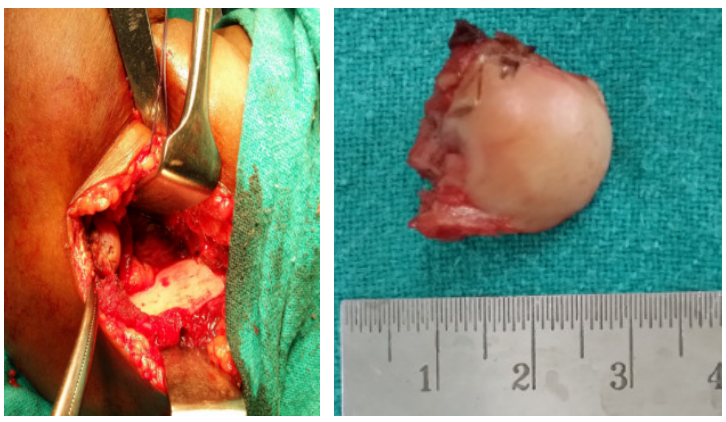

Fig. 3a: Peroperative photograph showing capitellum fracture; Fig.3b: Excised capitellum

The post operative outcome was uneventful. Active and active assisted elbow and forearm range of motion exercise was started from second postoperative day. She is able to flex and extend her elbow and supinate and pronate her forearm nearly through full range.

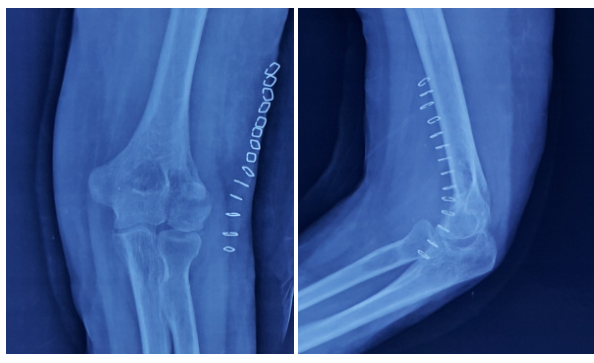

Fig.4: Postoperative radiograph

\section{Discussion}

Hahn-Steinthal fracture of the capitellum is $\operatorname{rare}^{3,9,10}$. It is important to emphasize that these fractures can be misdiagnosed simply because of bad radiologic examinations, inexperience in the interpretation of capitellum fragments and the bizarre appearance of the fracture, especially if there is considerable rotation associated with the displacement. In our case also, the diagnosis was missed initially. They can, however, lead to significant disability by limiting elbow motion if undiagnosed and untreated ${ }^{4}$. Excision of the fragment can lead to instability of the elbow ${ }^{11}$. Excision to prevent avascular necrosis is suggested by few authors ${ }^{4}$. Fragment excision due to fear of avascular necrosis or redisplacement can lead to radiohumeral osteoarthritis and instability of the elbow $^{3}$. Alvarez advocated excision of the fragment in 10 out of 14 cases $^{12}$.

On the basis of the time of presentation, clinical and radiological evidence, patient was diagnosed as avascular necrosis of capitellum and excision was performed. 
Had it not been a case of avascular necrosis, a displaced Hahn-Steinthal type 1 capitellum fracture such as described must be anatomically reduced to restore articular congruity and to minimize potential disablement. Due to lack of awareness in initial treating physician, the diagnosis of rare capitellum fracture was missed. This goal is more often achieved by early open reduction and internal fixation by headless screw. Being subarticular, it provides suitable interfragmentary compression and avoids incongruence, allowing early joint motion. It does not need to be removed.

The authors recognize limits of this case report, due to a short term follow-up and the absence of an index score to classify the clinical and radiological evolution.

\section{Conclusion}

Possibility of rare diagnosis such as capitellum fracture should also be kept in mind while treating elbow injuries. Radiograph should be carefully reviewed before labeling only soft tissue injury in case of complex joints like elbow.

\section{Consent}

Written informed consent was obtained from the patient for publication of this case report and related images.

\section{Conflict of interests}

No benefits in any form have been received or will be received from a commercial party related directly or indirectly to the subject of this article.

\section{References}

1. Bryan RS, Morrey BF. In: The elbow and its disorders. Morrey BF, editor. Philadelphia: WB Saunders; 1985. Fractures of the distal humerus; pp. 302-339.

2. Poynton AR, Kelly IP, O'Rourke SK. Fractures of the capitellum: a comparison of two fixation methods. Injury. 1998; 29:341-343. doi: 10.1016/S0020-1383(97)00107-1.

3. Pogliacomi F, Concari G, Vaienti E. Hahn-Steinthal fracture: report of two cases. Acta Biomed. 2005; 76:178184.

4. Letts $M$, Rumball $\mathrm{K}$, Bauermeister $\mathrm{S}$, Mclntyre W, D'Astous J. Fractures of the capitellum in adolescents. J Pediatr Orthop. 1997; 17:315-320.

5. Herring JA. Tachdjian's Pediatric Orthopaedics. Philadelphia: Saunders Elsevier; 2008.

6. Dubberley $\mathrm{JH}$, Faber $\mathrm{KJ}$, Macdermid JC, Patterson SD, King GJ. Outcome after open reduction and internal fixation of capitellar and trochlear 
fractures. J Bone Joint Surg Am. 2006; 88:46-54. Doi: 10.2106/JBJS.D.02954.

7. Mckee MD, Jupiter JB, Bamberger HB. Coronal shear fractures of the distal end of the humerus. J Bone Joint Surg Am. 1996; 78:49-54.

8. Ruchelsman DE, Tejwani NC, Kwon YW, Egol KA. Open reduction and internal fixation of capitellar fractures with headless screws. J Bone Join Surg Am. 2008; 90:1321-1329. Doi: 10.2106/JBJS.G.00940.

9. Johansson J, Rosman M. Fracture of the capitulum humeri in children: a rare injury, often misdiagnosed. Clin Orthop. 1980; 146:157-160.

10. Sodl JF, Ricchetti ET, Huffman GR. Acute osteochondral shear fracture of the capitellum in a twelve-year-old patient. A case report. J Bone Joint Surg Am. 2008; 90:629-633.

11. Grantham SA, Norris TR, Bush DC.Isolated fracture of the humeral capitellum. Clin Orthop.2006; 161:262269.

12. Alvarez E, Patel MR, Nimberg G, Pearlman HS. Fractures of the capitulum humeri. J Bone Joint Surg Am 1975; 57:1093-6. 